OPEN ACCESS

Edited by:

Pavel Kindlmann,

Charles University, Czechia

Reviewed by:

Bertrand Schatz,

Centre National de la Recherche

Scientifique (CNRS), France

Hans Jacquemyn,

KU Leuven, Belgium

${ }^{*}$ Correspondence:

Mariela Baldelomar

mariela.baldelomar.r@gmail.com Marco A. Molina-Montenegro marco.molina@utalca.cl

Specialty section:

This article was submitted to

Population and Evolutionary

Dynamics,

a section of the journal

Frontiers in Ecology and Evolution

Received: 29 July 2019 Accepted: 20 November 2019 Published: 10 December 2019

Citation:

Baldelomar M, Atala C and Molina-Montenegro MA (2019) Top-Down and Bottom-Up Effects Deployed by a Nurse Shrub Allow Facilitating an Endemic Mediterranean Orchid. Front. Ecol. Evol. 7:466 doi: 10.3389/fevo.2019.00466

\section{Top-Down and Bottom-Up Effects Deployed by a Nurse Shrub Allow Facilitating an Endemic Mediterranean Orchid}

\author{
Mariela Baldelomar $^{1 *}$, Cristian Atala ${ }^{2}$ and Marco A. Molina-Montenegro ${ }^{1,3,4 *}$ \\ ${ }^{1}$ Instituto de Ciencias Biológicas, Universidad de Talca, Talca, Chile, ${ }^{2}$ Instituto de Biología, Facultad de Ciencias, Pontificia \\ Universidad Católica de Valparaíso, Valparaíso, Chile, ${ }^{3}$ Centro de Estudios Avanzados en Zonas Áridas (CEAZA), Facultad de \\ Ciencias del Mar, Universidad Católica del Norte, Coquimbo, Chile, ${ }^{4}$ Centro de Investigación en Estudios Avanzados del \\ Maule (CIEAM), Universidad Católica del Maule, Talca, Chile
}

Aims: Facilitation among plant species occurs when the presence of one species, the so-called nurse, alters the environment in a way that enhances the growth, survival or reproduction of a second species. This positive association could be specie-specific and can have direct top-down (canopy) or bottom-up (soil) effects as well as indirect effects like higher tolerance against herbivory. The main objective of our study was to determine the positive interaction between the endemic Chilean orchid Bipinnula fimbriata and the nurse shrub Baccharis macraei in the Mediterranean ecosystem of Chile.

Methods: To assess the direct and indirect effects of the nurse, we conducted field and greenhouse experiments, respectively. In the field, we performed manipulative experiments assessing the nurse canopy and soil direct effects on the orchid. We measured microclimatic and edaphic variables within and outside nurses, and assessed survival, growth and photochemical efficiency (Fv/Fm) of the orchids. In the greenhouse, we performed experiments assessing the indirect effect of tolerance to simulated herbivory in orchids under nurse and open spaces conditions. We measured survival, flowering percentage, Fv/Fm, total biomass and jasmonic acid of the orchids.

Important Findings: We found more soil moisture and nutrients under the nurses, and higher photosynthetically active radiation, soil and air temperature in open spaces. Survival, growth and Fv/Fm were significantly higher in plants under the nurses, showing the top-down effect more importance than the bottom-up effect. In the greenhouse experiment, we found higher survival, Fv/Fm, flowering and biomass in orchids under the nurse treatment, independently of the imposed herbivory. Jasmonic acid was significantly higher in those individuals with herbivory and open spaces condition. We conclude that B. macraei acts as a nurse improving microclimatic and edaphic conditions that result in an increased survival, growth, physiological status and tolerance against herbivory for $B$. fimbriata present in the Mediterranean Chilean region.

Keywords: Baccharis, Bipinnula, facilitation, tolerance, orchid restauration 


\section{INTRODUCTION}

Plant-plant interactions have been pointed as a crucial driver for plant community composition and diversity. The role of positive interactions in population and community dynamics has received significant attention and is now widely recognized and included in many ecological models (Bruno et al., 2003; Michalet et al., 2006; Brooker et al., 2008; Wright et al., 2017). Positive interactions between plants are usually stated as facilitation, which co-occur with competition within the same community. The balance among facilitation and competition within a community varies with the life stages (Amghar et al., 2016), physiology and life-history of the interacting species (Maestre et al., 2009), indirect interactions and the intensity of abiotic/biotic stress (Michalet et al., 2006).

Facilitation has been defined as an interaction that benefits one species, and can have a beneficial, neutral or even harmful outcome to the facilitator species of the same trophic level (Callaway, 2007; Molina-Montenegro et al., 2016a), but as long as the effect on the other species is positive (sensu Bronstein, 2009) it is called facilitation. Therefore, the modes of facilitation can be mutualistic $(+/+)$ in a symmetric relationship or commensalistic $(+/ 0)$ in an asymmetric relationship (Brooker et al., 2008). The best-known examples of plant-plant facilitation involve a plant that ameliorate the harsh environmental conditions compared with the surrounding environment and/or gives protection from biotic or abiotic stress, enhancing the germination, growth and/or survival of seedlings in their immediate proximity (Callaway, 1995). Patterns of positive associations between seedlings of one species and sheltering adults of another species became commonly referred as the "nurse-plant syndrome" (see Callaway, 1995). In these interactions, the seedlings benefit from the microenvironment created by the adult plant (Flores and Jurado, 2003), which can alter its environment both above ("canopy or top-down effect") and below-ground ("soil or bottom-up effect") (Hunter and Price, 1992). The "canopy effect" includes mainly microclimatic amelioration and protection from herbivores (Gómez-Aparicio et al., 2005), whereas the "soil effect" involves the modifications that vegetation produces on chemical, physical, and biological soil properties (Mihoč et al., 2016). The importance of canopy and soil effects can vary depending on the considered species and differentially affect the physiological aspects of the beneficiary plant (Gómez-Aparicio et al., 2005). Besides the direct effect of the nurse over the amelioration of the abiotic stress, it is also important to consider the indirect effects that may arise because of enhanced tolerance against herbivory, due, for example, to increased nutrients when associated with the nurse. Therefore, to understand the real scope of the facilitation interaction, it is important to differentially study both direct and indirect effects. Surprisingly, the majority of studies consider only direct effects (but see Acuña-Rodríguez et al., 2006), but we understand the necessity of the evaluation of indirect effects, particularly in the Mediterranean zone, where the herbivory biotic stress is present.

Regarding the direct facilitation mechanisms are the temperature buffering, increase of soil moisture and nutrients (Molina-Montenegro et al., 2005; Cavieres et al., 2008), and physical protection from herbivory (Louthan et al., 2014), which are included in both top-down and bottom-up effects (Hunter and Price, 1992; Callaway, 1995; Flores and Jurado, 2003). Besides physical protection against herbivores, the nurse plant can also enhance the plant tolerance. Plant tolerance to herbivory has been defined as the ability to reduce the impact of damage on plant fitness (sensu Strauss and Agrawal, 1999), and it can be measured using either naturally occurring or manipulated herbivore damage (see Tiffin and Inouye, 2000). In this way, nurse plants might affect the tolerance of the beneficiary species in a positive way given that the highest level of tolerance is achieved in environments released from competition and/or with low abiotic stress (Strauss and Agrawal, 1999, but see Wise and Abrahamson, 2005 for an alternative idea). The potential mechanisms of tolerance to herbivory given by the nurses include increased leaf level photosynthetic activity, compensatory growth, activation of dormant meristems, utilization of stored reserves and phenological changes (Milchunas and Noy-Meir, 2002). In addition, jasmonic acid (JA) has been shown as a damage-inducible compound that elicits a diverse suite of defense responses when a plant is exposed to herbivory or mechanical damage (McCloud and Baldwin, 1997) and the jasmonic acid or octadecanoid pathway it is considered the major signal-transduction pathway involved in plant responses to herbivorous insects minimizing the fitness consequences of tissue loss (Howe and Schaller, 2008).

Facilitation is expected to prevail in plant communities with high abiotic stress or consumer pressure (Bertness and Callaway, 1994). Therefore, it is thought to be more frequent in harsh than in mild environments and appears to occur frequently in deserts and arid and semi-arid biomes (Flores and Jurado, 2003). The Chilean Mediterranean ecosystem is one of the 25 biodiversity hotspots (Myers et al., 2000), and because of its bioclimatic conditions, like summer drought (Rundel et al., 2016) and high levels of herbivory (Dallman, 1998; Gutiérrez et al., 2010), is considered a zone with high abiotic and biotic stress. Additionally, this ecosystem has been extensively altered by human activities and is subjected to erosion, plant cover removal, and presence of introduced herbivores like rabbits and cattle (Gutiérrez et al., 2010). Because of the relevance of drought as a stress factor, the amelioration of extreme summer climatic conditions such as elevated temperatures by shrub canopies has been proposed as a key facilitation mechanism in many Mediterranean ecosystems (Gómez-Aparicio et al., 2008; Molina-Montenegro et al., 2016b). The Baccharis genus has many species that act as nurses in different places, particularly, in Mediterranean Chile, where the species Baccharis macraei has been documented as a nurse shrub (Cuevas et al., 2013). In the Coastal areas of the Mediterranean zone of Chile it was previously observed (Atala et al., unpublished data) a positive spatial association between the endemic orchid Bipinnula fimbriata and native shrubs of the $B$. macraei species, therefore, suggesting that these shrubs may be acting as nurses for this endemic orchid. Given that the distribution area of this orchid is inside a hotspot (Myers et al., 2000; Novoa et al., 2015), it is important to confirm this facilitative interaction along with its effects for future restauration programmes involving this endemic orchid. 
The main goal of this study was to determine, by means of a higher survival and growth, the positive interaction between the shrubs B. macraei and the endemic orchid B. fimbriata in the Mediterranean region of Chile and the existence of direct (top-down, bottom-up) and/or indirect (increased tolerance to herbivory) effects. To accomplish this goal, we conducted manipulative experiments in field and greenhouse. Specifically, in the field, we differentially evaluated between canopy and soil nurse direct effects in the survival and growth as well as physiological status of orchid individuals. In the greenhouse, we evaluated the indirect effect of tolerance against herbivory by simulated herbivory in orchids located in treatments mimicking some factors of "nurse" and "open spaces" conditions.

\section{MATERIALS AND METHODS Study Site and Target Species}

We conducted our study in the coastal cliffs zone of Laguna Verde, Central Chile $\left(33^{\circ} 06^{\prime} \mathrm{S}, 71^{\circ} 40^{\prime} \mathrm{W}\right)$. This zone has a Mediterranean climate characterized by dry summers and rainfall concentrated during the mild winter, with mean annual temperatures ranging from 15 to $20^{\circ} \mathrm{C}$ and annual precipitation ranging from 413.1 to $460 \mathrm{~mm}$ with frequent water condensation in the mornings due to sea water evaporation and low clouds (Dallman, 1998; Luebert and Pliscoff, 2006). The dominant vegetation in the zone is represented by Coastal Mediterranean sclerophyllous forest dominated by Lithrea caustica, Cryptocarya alba, and Peumus boldus. The shrub-like stratum is mainly composed of Sophora sp., Lobelia sp., Puya sp., Crinodendron sp., Jubaea sp., Retanilla sp., and Baccharis sp. (Pliscoff and Fuentes, 2008). Other plants observed in the zone include terrestrial bromeliads like Puya spp., cacti and other annual species. However, the zone is found usually degraded with presence of Pinus sp. plantations and introduced Acacia and Eucalyptus species.

The facilitated species is the orchid Bipinnula fimbriata which is endemic to Chile with a distribution of $800 \mathrm{~km}$ along the central coastline (between $30^{\circ}$ and $36^{\circ} \mathrm{S}$ ) (Novoa et al., 2015). This species is perennial herb with a basal rosette and a flower spike that can reach $70 \mathrm{~cm}$ height containing many flowers. Such flowers present fimbriae sepals (hence is Spanish common name "flor del bigote," meaning "mustache flower") and greenish spotslike coloration in the labellum (Novoa et al., 2015). The study was done during its growing season between April and November 2017, when the aerial development of the orchid was visible. The nurse species is the evergreen dioic shrub Baccharis macraei belonging to the Asteraceae family that can reach $1.5 \mathrm{~m}$ height with simple and alternate leaves that are serrated, capitulate white flowers and achene fruits (Riedemann et al., 2014).

\section{Spatial Association of the Facilitated Orchid}

To assess the natural pattern of association between facilitated orchid and nurse shrub, we recorded the number of orchid individuals (rosettes) within and outside of nurses. We recorded rosettes $/ \mathrm{m}^{2}$ by using $20(1 \times 1 \mathrm{~m})$ quadrants within nurses and other 20 quadrants outside of them.

\section{Microclimatic Measurements}

In order to establish how B. macraei modifies the microclimatic conditions under its canopy, we measured air and soil temperature, soil moisture, and photosynthetic active radiation (PAR) within and outside nurses. In addition, we measured the nutrient content and organic matter in the soil within and outside nurses. The temperature measurements were realized $10 \mathrm{~cm}$ above and below ground with a digital thermometer (Vichy, Model DM6804A+) with ten repetitions per microsite. Soil moisture was measured $15 \mathrm{~cm}$ below ground with a soil moisture sensor (Model ISR-300, Irrometer Company, Riverside, California-USA) after a $2 \mathrm{~h}$ period of stabilization. We measured PAR with a light meter (Li-cor model Li-250) at 14:00 pm with 20 repetitions per microsite. All measurements were done oncea-month for 4 months.

To analyse soil characteristics between microsites, we sampled $300 \mathrm{~g}$ of soil at $10 \mathrm{~cm}$ depth with five repetitions per microsite. Afterward, we analyzed: organic matter, available nitrogen, available potassium, and available phosphorus in all soil samples. All soil measurements were conducted in the Laboratory of Soils Analyses at the Universidad de Concepción, Chillán.

\section{Manipulative Field Experiment}

We conducted a transplant experiment to evaluate the nurse effect of $B$. macraei on the ecophysiological performance (survival, growth, and photochemical efficiency) of the endemic orchid. We located orchids that were in the early stage of maturation or seedlings, called rosettes, to perform the experiment. All the 100 rosettes considered for the study were excavated and left without the soil around the roots by manually removing the soil. Although there was a difference between the initial sizes of the rosettes, measured as the diameter of the rosettes, we mixed all sizes within each treatment to avoid differences among treatments $\left[F_{(3,96)}=2.13 ; p=0.62\right]$. We put each rosette inside plastic pots with $3 \mathrm{~kg}$ of soil obtained under nurses or with soil obtained in open spaces depending on the treatment. We performed four treatments with 25 repetitions each: (i) rosettes with nurses soil located in open spaces (ON), (ii) rosettes with nurses soil located under the nurses (NN), (iii) rosettes with open spaces soil located in open spaces (OO), and (iv) rosettes with open spaces soil located under the nurses (NO), following the transplant methodology realized by MolinaMontenegro et al. (2016b). We selected 25 visually healthy adult nurses, similar in diameter (between 1.0 and $1.5 \mathrm{~m}$ ), with enough space underneath their canopies to fit the pots. We located two pots at the middle portion between the trunk and the edge of canopy projection of each nurse and two pots in open spaces near the nurses (between 2 and $3 \mathrm{~m}$ from canopy edge of any nurse). The nurse shrubs were separated approximately $5 \mathrm{~m}$ apart, and each pot in both under canopy and in open spaces had $30 \mathrm{~cm}$ between them to avoid overlapping. In order to generate similar protective conditions against natural herbivory in the four treatments, we protected the treatments located outside the shrubs ( $\mathrm{i}$ and iii) with a wire mesh cylinder $(1 \mathrm{~m}$ diameter $\mathrm{x} 1 \mathrm{~m}$ tall, $25 \mathrm{~mm}$ mesh) imitating the shrub canopy protection of the treatments ii and iv. Final measurement did not show differences between percentages of aerial herbivory between 
treatments located inside and outside canopies $\left[F_{(1,3)}=11.8 ; p\right.$ $=0.29$ ], guaranteeing the uniformity of the treatments. The four treatments involving each of the 25 nurses were considered as a group. The transplants were realized at the beginning of the growing season.

The experiment was carried out during the above-ground phase of the orchids that lasted 7 months. Survival and growth were assessed as parameters related to fitness and photochemical efficiency of photosystem II (Fv/Fm) was considered as a proxy of physiological status. The survival was recorded monthly, considering that the plant was dead if it presented more than $90 \%$ of damaged tissue. Growth was calculated as the difference between the initial and final rosette leaves diameter, we took photographs of the rosettes and estimate the diameters with the program Image J. The parameter $\mathrm{Fv} / \mathrm{Fm}$; where $\mathrm{Fv}=[\mathrm{Fm}-$ $\left.\mathrm{F}_{0}\right], \mathrm{Fm}=$ maximum fluorescence yield, and $\mathrm{F}_{0}=$ minimum fluorescence yield) accounts for the potential quantum efficiency of photosystem II that is used as a sensitive indicator of plant photosynthetic performance. Its optimal values are around 0.83 , with lower values indicating that the plant has been exposed to stress and presents photoinhibition (Maxwell and Johnson, 2000). Fv/Fm was measured at midday every month with a fluorometer (Handy and Pocket PEA Chlorophyll, Hansatech Instruments) with a light intensity of $3,000 \mu \mathrm{mol} \mathrm{m} \mathrm{m}^{-2} \mathrm{~s}^{-1}$ in one visually healthy leaf per individual that was previously exposed to darkness for $15 \mathrm{~min}$.

\section{Greenhouse Experiment}

To determine if the facilitative effects induced by B. macraei on B. fimbriata are indirect; i.e., enhance tolerance to herbivory, we performed a greenhouse experiment with simulated herbivory in two moisture and edaphic conditions that simulated the nurselike and open spaces conditions. To represent soil moistures under nurse-like and open spaces conditions, we conducted a manipulative experiment in pots filled with soil from both microsites. We water the pots with 5 different volumes $(20,40$, 60,80 , and $100 \mathrm{ml}$ ) every 2 days for 2 months. Using a soil moisture sensor (Model ISR-300, Irrometer Company, Riverside, California-USA) we determined that a watering of $40 \mathrm{ml}$ every 2 days would represent the moisture underneath the nurse, and $20 \mathrm{ml}$ every 2 days would represent the moisture from open spaces (see Table $\mathbf{1}$ ).

We collected 48 rosettes (between 45 and $50 \mathrm{~cm}$ height) from the study area: 24 orchids from open spaces and transplanted them to $0.5 \mathrm{~L}$ plastic pots with a mix of its original soil (open spaces) and sand (2:1 v:v); and 24 orchids from beneath nurse shrubs and transplanted them to pots with a mix of nurse-soils and sand (2:1 v:v.). We left the pots inside the greenhouse for a week with daily irrigation for stabilization.

After, the 24 rosettes with nurse-soil were irrigated with $40 \mathrm{ml}$ every 2 days and the 24 rosettes with open spaces soil were irrigated with $20 \mathrm{ml}$ every 2 days, thereby representing the nurse and open spaces conditions, respectively. Four weeks later, we imposed $25 \%$ of herbivory damage-mimicking the herbivory percentage observed in the field-at half of the rosettes in both conditions. To reach this percentage of damage we removed $50 \%$ of the foliar tissue with scissors along the mid vein in half of the leaves of each rosette following the methodology used by Acuña-Rodríguez et al. (2006). Obtaining therefore four treatments: 12 orchids in nurse-like conditions without herbivory $(\mathrm{N}), 12$ orchids in nurse-like conditions with herbivory $(\mathrm{NH}), 12$ orchids in open spaces conditions without herbivory $(\mathrm{O})$ and 12 orchids in open space conditions with herbivory $(\mathrm{OH})$.

We measured every week the survival, flowering and Fv/Fm. The jasmonic acid (JA) concentration in leaves and the total dry biomass were considered as a proxy of tolerance or compensation mechanisms to herbivory damage since it is known that mobilization (i.e., production of phytohormones) and storage (i.e., growth) of resources contributes to plant tolerance of herbivory (Milchunas and Noy-Meir, 2002; Howe and Schaller, 2008). JA determination was done using approximately $50 \mathrm{mg}$ of each lyophilized plant sample with addition of the $1 \mathrm{ml}$ of pre-warmed $\left(65^{\circ} \mathrm{C}\right)$ methanol and the extraction proceeded for $60 \mathrm{~min}$ at room temperature under gentle shaking (for more details, see Loba and Pollmann, 2017). In brief, each sample was supplemented with $50 \mathrm{pmol}\left[{ }^{2} \mathrm{H}_{5}\right]$-JA (stable isotopelabeled internal standards). Cell-free supernatants were dried using an oven under vacuum and pre-purified for subsequent gas chromatography-mass spectrometry analysis (ISQ single 7K-VPI, Thermo Fisher Scientific Inc.). Finally, at the end of the experiment, we collect all tissue (root and shoot) of each orchid and over-dried at $60^{\circ} \mathrm{C}$ for $96 \mathrm{~h}$ to obtain the total dry biomass. All leaves fallen or dead (naturally dried) during the experiment were dried and added to the correspondent replicate. Inter-pot distance was $20 \mathrm{~cm}$ and all pots were randomly arranged each week inside the greenhouse to avoid overlapping in their canopies and any possible block effect.

\section{Data Analysis}

The abundance of orchids distributed within and outside nurses was evaluated with one-way ANOVA. Microclimatic data (soil and air temperature, soil moisture and PAR) were analyzed with repeated measures ANOVA to compare the effect of the nurses along time. Soil nutrients and organic matter were analyzed with one-way ANOVAs. Survival curves recorded in the field and greenhouse were analyzed with a Kaplan-Meier test and the statistical significance between them was estimated with a CoxMantel test (Fox, 1993). Field and greenhouse Fv/Fm data were analyzed with repeated measures ANOVA. Growth data in the field was compared with two-way ANOVAs. JA concentration and total biomass data in the greenhouse were analyzed and compared with two-way ANOVAs. Flowering data was analyzed with a Chi-square test. All response variables presented a normal distribution and homogeneity of variances which were analyzed with the Shapiro-Wilk and Bartlett tests, respectively; fulfilling ANOVA assumptions (Sokal and Rohlf, 1995). Comparisons between treatments were evaluated using a posteriori Tukey HSD tests. All ANOVAs were performed using the R Software (RStudio interface v. 0.99.896) and the graphics were done using Statistical (v.6.0; Statsoft, USA). 
TABLE 1 | One-way ANOVAs of the microclimatic variables measured under nurses and in open sites.

\begin{tabular}{|c|c|c|c|c|}
\hline Microclimatic variable & Under nurses & Open sites & $\mathbf{F}$ & $p$-value \\
\hline Air temperature ${ }^{\circ} \mathrm{C}$ & $21 \pm 4.2(C V=0.20)$ & $20.6 \pm 4.4(C V=0.21)$ & 0.194 & 0.661 \\
\hline Soil temperature ${ }^{\circ} \mathrm{C}$ & $13.4 \pm 2.2(\mathrm{CV}=0.17)$ & $21.4 \pm 11.3(C V=0.53)$ & 9.559 & 0.004 \\
\hline Soil moisture KPa & $12.8 \pm 7.3(\mathrm{CV}=0.35)$ & $25.4 \pm 6.9(\mathrm{CV}=0.28)$ & 7.859 & 0.023 \\
\hline Radiation PAR $\mu \mathrm{mol} \mathrm{m} \mathrm{m}^{-2} \mathrm{~s}^{-1}$ & $227 \pm 353.5(\mathrm{CV}=1.56)$ & $1051.9 \pm 660(C V=1.01)$ & 84.35 & $<0.001$ \\
\hline
\end{tabular}

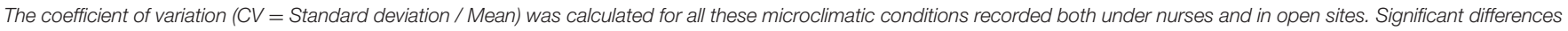
are highlighted in bold.

\section{RESULTS}

\section{Spatial Association of the Facilitated Orchid}

The orchid density inside nurse shrubs was 3 times higher than outside of them, being this difference statistically significative $\left[F_{(1,39)}=89.32 ; P<0.001\right]$. Specifically, the density within of nurses was $7.6 \pm 1.3$ individuals $/ \mathrm{m}^{2}$ and outside shrubs was $2.5 \pm 0.5$.

\section{Microclimatic Measurements}

From the four microclimatic variables registered in the field, three showed significant differences, affected both by microsite and time (Tables 1, 2). PAR was the variable that differed most between microsites, presenting values almost five-times higher in open spaces in comparison with under nurses' microclimate. Soil moisture showed 50\% higher values under nurses than in open spaces. Finally, soil and air temperature data presented significantly higher values in open spaces than beneath nurses (Tables 1, 2). Soil variables that showed a significant difference between microsites were: available nitrogen, available potassium and organic matter; presenting higher values in the soil located under the nurses in comparison with open spaces (Table 3).

\section{Manipulative Field Experiments}

The photochemical efficiency ( $\mathrm{Fv} / \mathrm{Fm})$ of orchids was affected by nurse canopy, time and their interaction $\left[F_{(1,210)}=28.61 ; p<\right.$ $0.001 ; F_{(4,210)}=9.95 ; p<0.001$ and $F_{(4,210)}=3.61 ; p=0.007$, respectively]. Nurse soil, however, did not affect orchids Fv/Fm $\left[F_{(1,210)}=0.38 ; p=0.54\right] . \mathrm{Fv} / \mathrm{Fm}$ was higher in the orchids underneath the nurse canopy, independently of the soil origin, in comparison with the orchids in open spaces that showed lower $\mathrm{Fv} / \mathrm{Fm}$ on average and over time (Figure 1A). Survival of B. fimbriata individuals was significantly different in the four treatments (Cox-Mantel test $=72.3 ; p<0.001$ ). Orchids under nurse canopy and with soil from nurses presented the highest survival, followed by individuals under nurse canopy with soil from open spaces. Finally, the rosettes transplanted with nurse soil and placed in the open spaces presented complete mortality at the end of the experiment as well as the orchids with soil from open spaces and placed in open spaces (Figure 1B).

On the other hand, both nurse factors, top-down and bottomup, had a significant effect on orchid growth $\left[F_{(1,94)}=38.28\right.$; $p<0.001$ and $F_{(1,94)}=9.11 ; p<0.01$, respectively]. Growth was significantly higher in orchids that were within the nurse canopy and/or nurse soil in comparison with orchids without
TABLE 2 | Repeated measures ANOVAs of microclimatic variables (air temperature, soil temperature, moisture, and radiation).

\begin{tabular}{|c|c|c|c|c|}
\hline Source of variation & df & MS & $\mathbf{F}$ & $p$-value \\
\hline \multicolumn{5}{|l|}{ Air temperature ${ }^{\circ} \mathbf{C}$} \\
\hline Location (L) & 1 & 10.65 & 5.35 & 0.231 \\
\hline Time $(T)$ & 3 & 569.57 & 285.91 & $<0.001$ \\
\hline $\mathrm{L} \times \mathrm{T}$ & 3 & 6.05 & 3.03 & 0.322 \\
\hline Residuals & 112 & 1.99 & & \\
\hline \multicolumn{5}{|l|}{ Soil temperature ${ }^{\circ} \mathbf{C}$} \\
\hline Location (L) & 1 & 786.43 & 1052.19 & $<0.001$ \\
\hline Time $(T)$ & 1 & 1044.17 & 1397.02 & $<0.001$ \\
\hline $\mathrm{L} \times \mathrm{T}$ & 1 & 695.64 & 930.72 & $<0.001$ \\
\hline Residuals & 26 & 0.75 & & \\
\hline \multicolumn{5}{|l|}{ Soil moisture \% } \\
\hline Location (L) & 1 & 396.90 & 17.13 & 0.014 \\
\hline Time $(T)$ & 2 & 41.03 & 1.77 & 0.281 \\
\hline$L X T$ & 2 & 114.63 & 4.95 & 0.083 \\
\hline Residuals & 4 & 23.17 & & \\
\hline \multicolumn{5}{|c|}{ Radiation $\left(\mu \mathrm{mol} \mathrm{m} \mathrm{m}^{-2} \mathrm{~s}^{-1}\right)$} \\
\hline Location (L) & 1 & 24811937 & 999.24 & $<0.001$ \\
\hline Time $(\mathrm{T})$ & 4 & 8362876 & 336.79 & $<0.001$ \\
\hline$L X T$ & 4 & 1449925 & 58.392 & $<0.001$ \\
\hline Residuals & 137 & 24831 & & \\
\hline
\end{tabular}

The main effects were location (under nurses or open spaces) and time. Significant differences are highlighted in bold.

any effect of the nurses (Figure 2). The orchids under nurse canopy were not so negatively affected by the absence of nurse soil in comparison with the orchids located in open spaces, which presented the lowest growth (Figure 2).

\section{Greenhouse Experiment}

Rosettes $\mathrm{Fv} / \mathrm{Fm}$ was affected by condition (nurse-like or open spaces), herbivory and time $\left[F_{(1,264)}=163.14 ; p<0.0001\right.$; $F_{(1,264)}=15.56 ; p<0.0001$ and $F_{(5,264)}=168.37 ; p<0.0001$, respectively]. It was also affected by the interaction between condition (nurse-like or open spaces) and time $\left[F_{(5,264)}=\right.$ 29.12; $p<0.0001]$. Fv/Fm was significantly higher in the orchids under nurse-like conditions, and the orchids without imposed herbivory presented the higher values at the end of the experiment. Although orchids of the four treatments showed a decrease in the $\mathrm{Fv} / \mathrm{Fm}$ value over time, orchids in open spaces 
TABLE 3 | Soil nutrients available (nitrogen mg/Kg, Phosphorus mg/Kg, potassium $\mathrm{mg} / \mathrm{Kg}$ ) and organic matter (\%) under nurses and in open spaces.

\begin{tabular}{lcccc}
\hline Soil variable & Under nurses & Open spaces & F & $\boldsymbol{p}$-value \\
\hline Nitrogen & $13.38 \pm 4.30$ & $4.06 \pm 0.98$ & 22.38 & $\mathbf{0 . 0 0 1 5}$ \\
Phosphorus & $6.34 \pm 2.64$ & $4.28 \pm 0.83$ & 2.77 & 0.1344 \\
Potassium & $452.66 \pm 87.98$ & $302.1 \pm 51.79$ & 10.88 & $\mathbf{0 . 0 1 0 9}$ \\
Organic matter & $4.61 \pm 0.69$ & $3.15 \pm 0.45$ & 15.76 & $\mathbf{0 . 0 0 4 1}$
\end{tabular}

Significant differences are highlighted in bold.

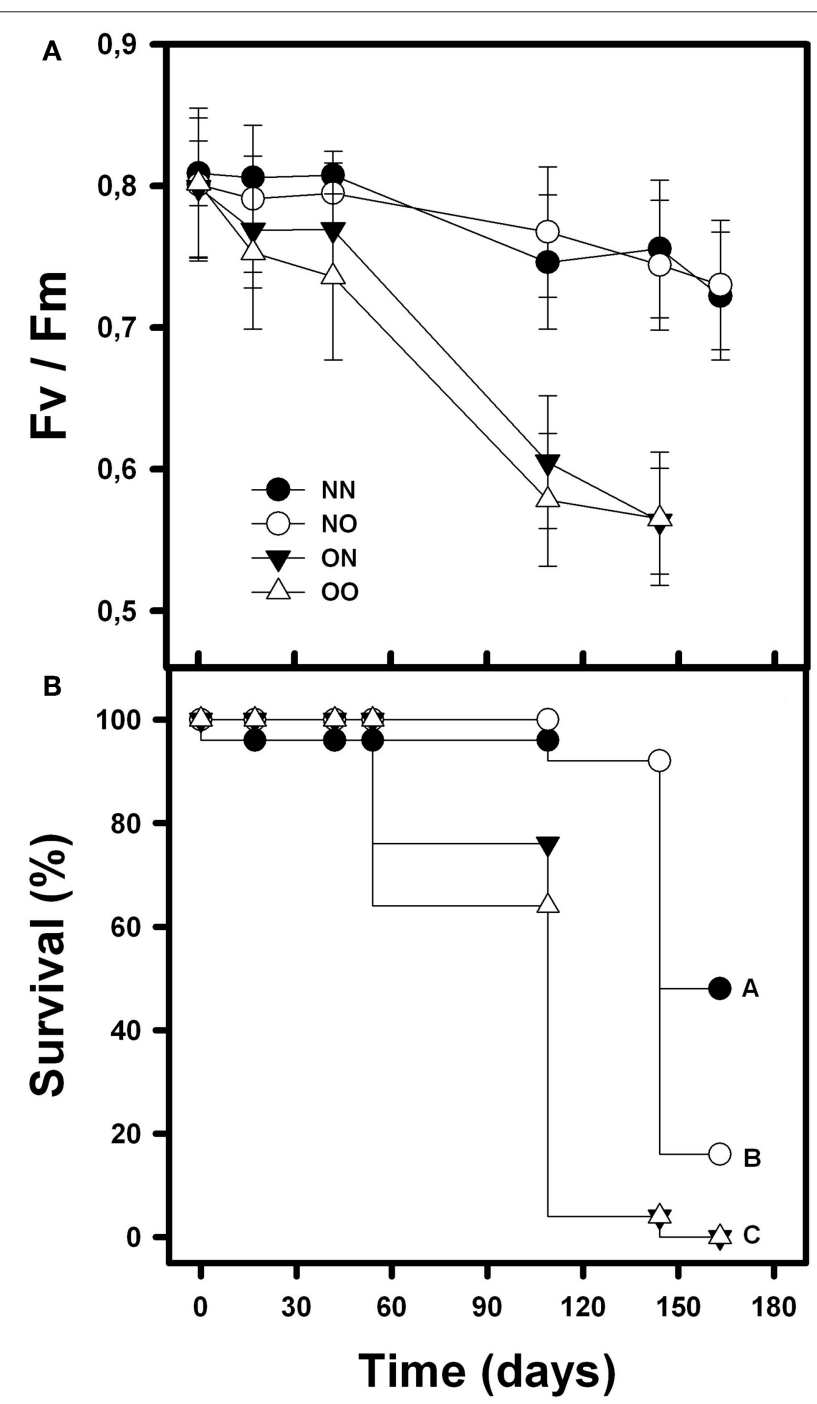

FIGURE 1 | Mean survival percentage (A) and photochemical efficiency "Fv/Fm" (B) of B. fimbriata rosettes along time and under the four different treatments in the field: under nurse canopy + soil from nurses (NN), under nurse canopy + soil from open spaces (NO), in open spaces + soil from nurses $(\mathrm{ON})$ and in open spaces + soil from open spaces $(\mathrm{OO})$. Different letter indicates significant differences.

conditions presented significantly lower values (Figure 3A). On the other hand, survival of $B$. fimbriata rosettes was significantly different between the treatments (Cox-Mantel test $=12.9 ; p=$

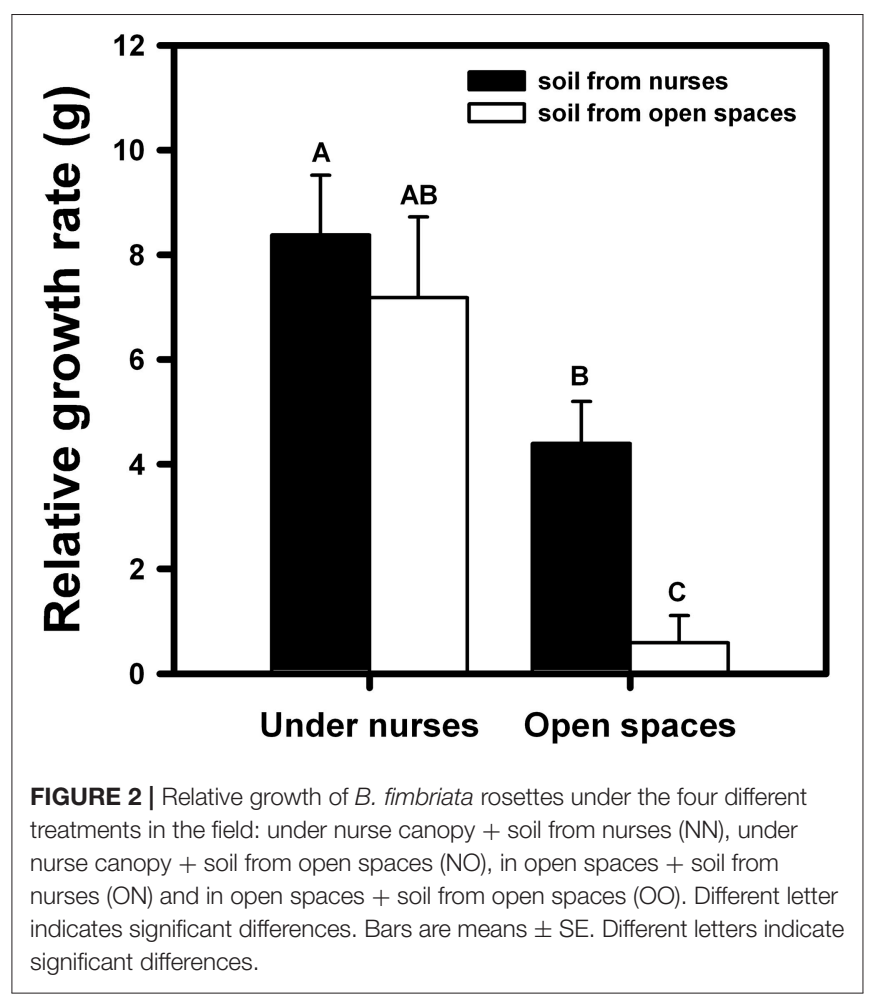

0.047; Figure 4). Individuals with nurse-like conditions showed significantly higher survival percentage compared with those placed in open space conditions independently of the herbivory damage (Figure 3B).

Similarly, JA concentration in the leaves was affected by condition (nurse-like or open spaces), herbivory and time $\left[F_{(1,95)}\right.$ $=24.36 ; p<0.0001 ; F_{(1,95)}=347.16 ; p<0.0001$ and $F_{(6,95)}$ $=86.85 ; p<0.0001$, respectively]. It was also affected by the interactions of the three factors. JA concentration remained low in individuals without imposed herbivory (Figure 4). In opposite way, plants subjected to herbivory showed a significant increase in JA seven days after herbivory, with the rosettes in the open spaces' conditions presenting the highest increase. Finally, after 44 days, the JA concentration in these rosettes decreased, reaching initial values (Figure 4).

The flowering of the orchids was different between the four treatments $\left(\mathrm{chi}^{2}=20.8 ; p=0.001\right)$. It was higher in plants under nurse-like conditions, independently of the imposed herbivory damage, presenting 50\% flowering in orchids without herbivory, and $33.3 \%$ in orchids with herbivory. The orchids in the open space condition without herbivory presented only $16.7 \%$ flowering, and individuals in the open space conditions with herbivory did not flower at all.

Total biomass of the orchids was affected both by the condition (nurse-like or open spaces) and the imposed herbivory $\left[F_{(1,27)}=22.37 ; p<0.0001\right.$ and $F_{(1,27)}=8.31 ; p=0.008$, respectively]. The orchids under nurse-like conditions presented higher biomass in comparison with the orchids in open 


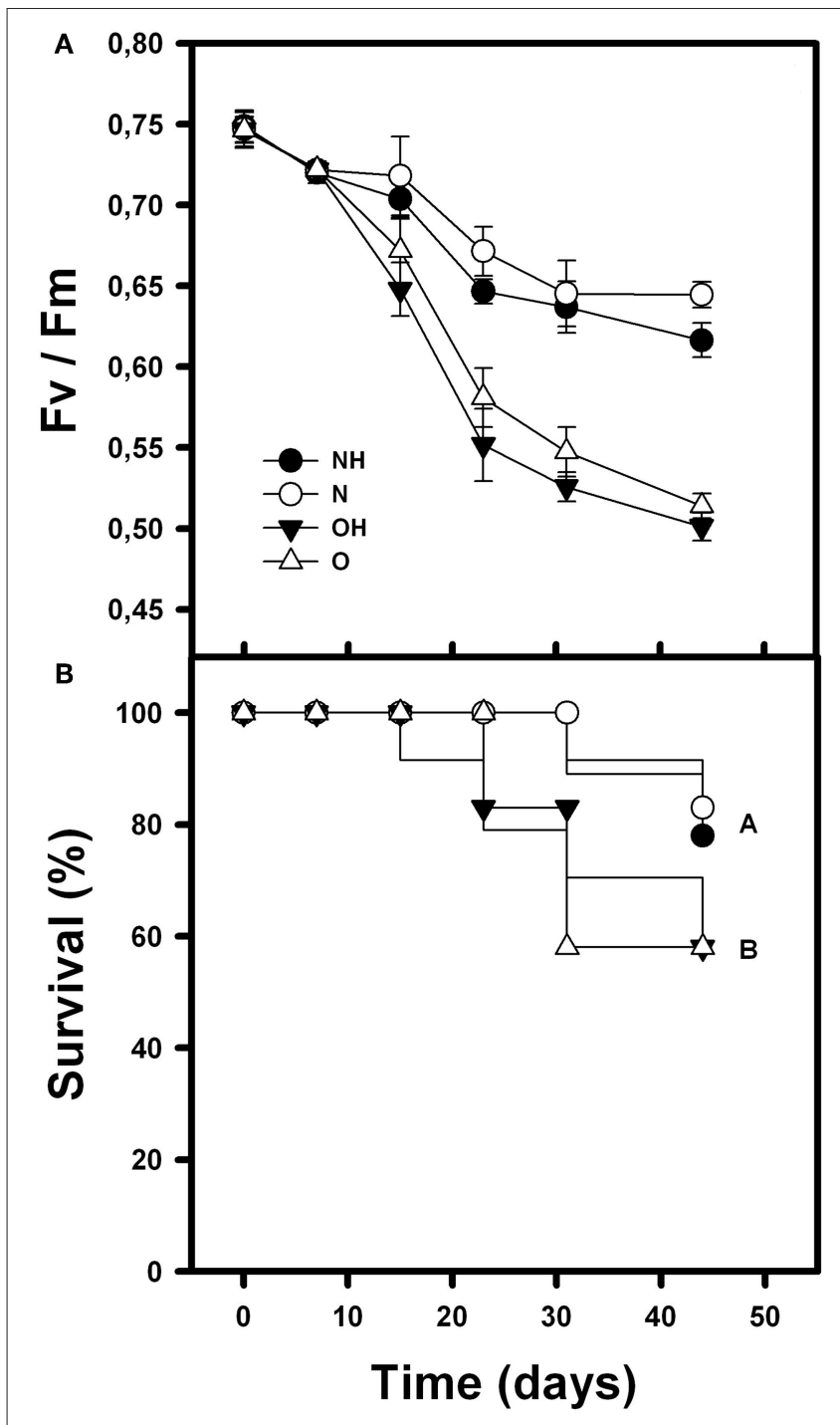

FIGURE 3 | Mean survival percentage (A) and photochemical efficiency "Fv/Fm" (B) during the recording time of $B$. fimbriata rosettes under the four treatments in the greenhouse: nurse-like conditions with $(\mathrm{NH})$ and without $(\mathrm{N})$ herbivory, and open spaces conditions with $(\mathrm{OH})$ and without $(\mathrm{O})$ herbivory. Different letters indicate significant differences.

spaces conditions (Figure 5). Moreover, orchids with imposed herbivory presented a higher biomass under nurse-like conditions in comparison with open spaces conditions (Figure 5).

\section{DISCUSSION}

Facilitation has been more reported in medium to high environmental stress places both by top-down and bottomup effects. In our study, we found a facilitative interaction in the stressful Mediterranean zone dominated by the canopy effect of the nurse which was the main responsible for the amelioration of the stress. Mediterranean climates

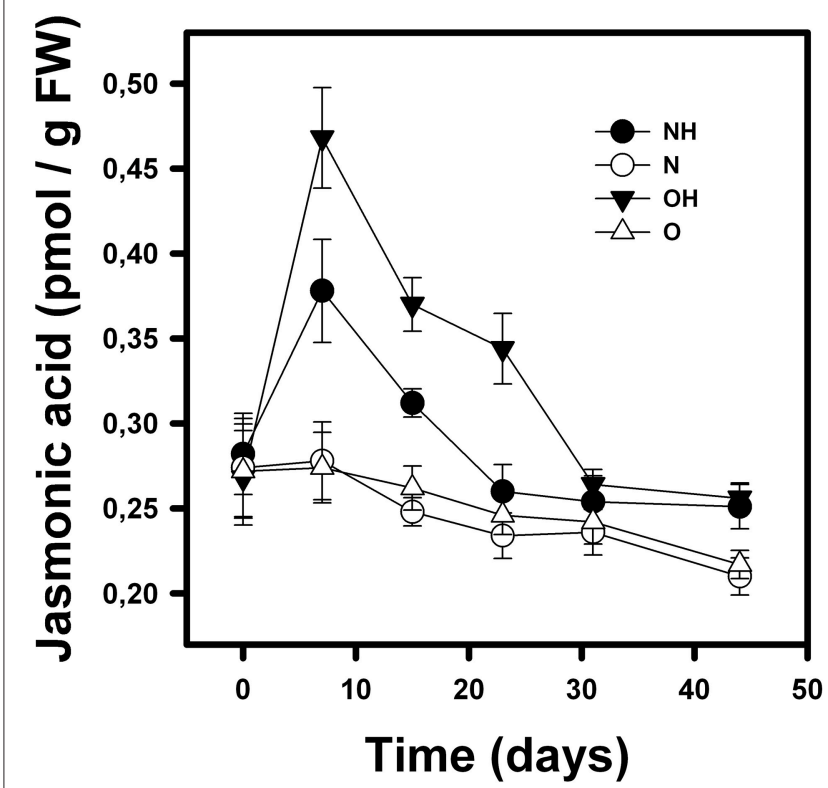

FIGURE 4 | Mean ( \pm 1 SD) of jasmonic acid concentration (pmol/gPF) in B. fimbriata rosettes under the four treatments in the greenhouse: nurse-like conditions with $(\mathrm{NH})$ and without $(\mathrm{N})$ herbivory, and open spaces conditions with $(\mathrm{OH})$ and without $(\mathrm{O})$ herbivory.

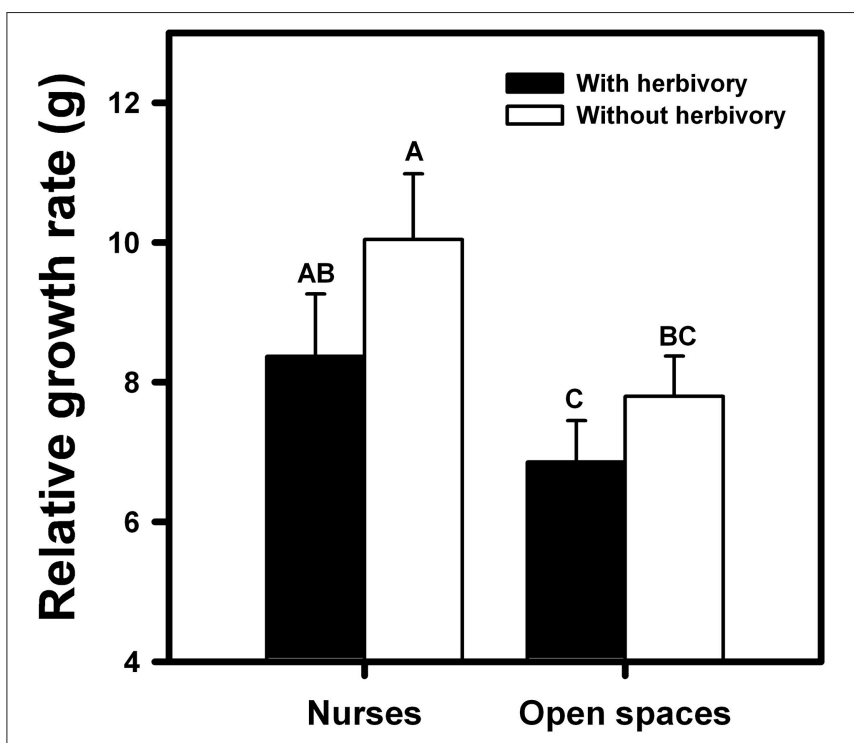

FIGURE 5 | Relative biomass of $B$. fimbriata rosettes in the four greenhouse treatments: nurse-like conditions with (black bar) and without (white bar) herbivory, and open spaces conditions with (black bar) and without (white bar) herbivory. Different letters indicate significant differences. Bars are means \pm SE. Different letters indicate significant differences $(P<0.01$, Tukey test).

imposes high temperatures with elevate irradiance, causing a summer drought stress in plants growing in this ecosystem (Dallman, 1998). Therefore, the higher moisture and lower PAR, along with milder soil and air temperatures, indicators of a strong top-down effect, are associated 
with a higher survival and growth of B. fimbriata in this stressful zone.

Although we found considerably less PAR under the nurses, they seem to bring enough light through their canopies to support the establishment and survival of the rosettes and allow them a higher growth and $\mathrm{Fv} / \mathrm{Fm}$ than in open spaces. Although light is inhibitory to germination in many terrestrial orchids and even some epiphytic species, the correlation of canopy coverage with successful germination and seedling development could be attributed to light avoidance and preference of a mesic shaded microclimate (Kartzinel et al., 2013). Besides the microclimatic amelioration at canopy level, nutrients also have been indicated to be more abundant in the soil under nurses (Mihoč et al., 2016). In addition, it has been demonstrated that nurse shrub in a semi-arid ecosystem increased the survival and growth of different plant species by enhance of soil nutrients availability (Molina-Montenegro et al., 2016b). Similarly, in our study zone, we found more organic matter, and available nitrogen and potassium in soil underneath the nurses. It has been shown that higher level of nutrients enhance the growth and flowering of different orchid species (Bichsel et al., 2008), probably due that a higher availability of nutrient reduce the costs associated to maintaining the symbiosis with fungus as well as the plantfungus transfer of nutrients (Cameron et al., 2008). Thus, higher nutrient availability in the soil under nurses could be a key factor to explain the greater performance by part of the facilitated orchids. The higher growth observed in the rosettes underneath the nurse may have been because of this higher soil nutrients and moisture or because the leaves increased the area to receive enough light for photosynthesis, or both (García-Cervigón et al., 2015). Considering that the PAR under the nurses was lower and that $\mathrm{Fv} / \mathrm{Fm}$ was higher in the rosettes underneath the nurse, we could assume that the growth in the rosettes leaves was not (only) a response to shading. Moreover, the $\mathrm{Fv} / \mathrm{Fm}$ decreases in the presence of stress, like photoinhibition, and it can also affect the growth of some orchids (Stancato et al., 2002), but that was not the case in our study because orchids growing underneath the nurse presented Fv/Fm values consistent with no- or low stress.

Although we observed a positive effect induced by the canopy of nurse shrubs on the survival and growth of facilitated orchids, should be considered the indirect effects on other components related with fitness as fruit set. It has been shown that orchid species of Bipinula genus are highly dependent from pollination service for reproduction and fruit set (Ciotek et al., 2006). Thus, the canopy could be a negative factor for some fitnessrelated traits if avoid the interaction between the orchids and pollinators. On the other hand, the attraction of pollinators is modulated by semiochemicals compounds which are reduced under low light conditions (Bohman et al., 2016), as those find under canopy of nurses. Thus, additional experiments should be conducted in order to unravel the final outcome of this plant-plant interaction beyond of vegetative traits assessed, but considering other fitness-related traits and even about of the population dynamic.

Regarding the indirect effects, we observed that B. fimbriata presented many of the reported herbivory tolerance mechanisms: increased survival, increased $\mathrm{Fv} / \mathrm{Fm}$, and compensatory growth observed as higher flowering and biomass (Milchunas and Noy-Meir, 2002). Although our plants did not experience necessarily- the timing, distribution, and pattern of damage that they would experience in a natural population, the manipulative herbivory imposed in our study allowed us to control the level of damage (25\% as observed in natural conditions) and to estimate the tolerance more accurately (Tiffin and Inouye, 2000). In addition, JA production induced by the biotic stress was higher in the herbivory treatments, in agreement with the literature (Howe and Schaller, 2008). Nevertheless, the triggered response was higher in orchids that were in the open spaces/stressful conditions. One possible explanation for this is that the expression of induced plant defense responses is mediated by responses to abiotic stress and JA, in particular, is a common key signaling molecule, involved both in biotic and abiotic stress (Ramegowda and SenthilKumar, 2015). Thus, the exposure of plants to simultaneous abiotic and biotic stress can result in tolerance to both stress due to inherent ability of plants to induce unique tailored strategies, or contrarily, it can make plants more susceptible to both stress due to exacerbation of damage caused by one stress on other (Ramegowda and Senthil-Kumar, 2015). Therefore, in our study, the previous stress exposure of the orchids (less moisture) could have had an additive effect on the JA production so that the orchids could deal with both stresses simultaneously. But then, experiments assessing the JA quantity before and after the stress are needed to confirm this supposition.

Another indirect effect that may have occurred in our study, but not previously expected, may have involved the mycorrhizal benefit due to better soil conditions under the nurse. It is known that orchids have symbiotic associations with mycorrhizal fungi, usually orchidioid, which allow their seeds to germinate since they are mycoheterotrophic at early stages (Smith and Read, 2008), lacking reserves in their very small seeds, being also important in adults (Atala et al., 2015). Besides the biotic interaction with the mycorrhizas, orchid germination is affected by abiotic factors that can affect directly on the orchid seeds/seedlings or indirectly through the availability of fungi and carbon source (Rasmussen et al., 2015). B. fimbriata is associated with at least five different mycorrhizal fungi (Steinfort et al., 2010). Therefore, the higher abundance and better physiological status of the rosettes underneath the nurses in our study could be not only due to the direct effect of the nurse on the orchids but also to the indirect effect in the higher mycorrhizal diversity and/or abundance as observed in a semiarid Mediterranean system, also in Chile (Molina-Montenegro et al., 2016a), which could enhance the germination rate of orchids in this microsite (Steinfort et al., 2010).

Because traits related to competitive ability or stress-tolerance of co-existing species and stress type/ level can influence the net interaction, we analyzed these factors in our study to see if they met the predicted relationship suggested by Maestre et al. (2009) in their refined stress gradient hypothesis (SGH). Our study species show a stress tolerant type: $B$. macraei is considered drought-tolerant (Badano et al., 2005) and $B$. 
fimbriata is considered stress tolerant ruderal (Hágsater and Dumont, 1996). Therefore, considering that the stress factors in our study are resource-driven (i.e., water), we could expect that the interaction outcome between our study species would be negative at low stress or positive at medium-high stress (Maestre et al., 2009). The study site is considered a semiarid ecosystem (Luebert and Pliscoff, 2006) with an average annual precipitation ranging from 413.1 to $460 \mathrm{~mm}$ (Dallman, 1998), imposing a medium stress to its biota. Hence, the predicted positive interaction between two stress-tolerant species under medium resource stress was observed as a nurse effect between the studied species. This information can be used in restoration programmes for this endemic orchid especially in the initial stages of establishment and development of the orchid in a novel habitat. Nonetheless, it is important to consider that the net interaction could change if the intensity of the stress changes in the zone. A decrease in rainfall is predicted in the study region for the next years (Quintana and Aceituno, 2012), which may turn the water stress from medium to high, increasing the facilitative interaction due to the higher ecological relevance of nurses or changing the net interaction to negative if the stress level overpass the shelter action of nurses (see Michalet et al., 2006). Thus, more studies should be conducted considering future climate change scenarios to unravel these hypotheses and its consequences for this endemic orchid in the Mediterranean ecosystem.

\section{REFERENCES}

Acuña-Rodríguez, I. S., Cavieres, L. A., and Gianoli, E. (2006). Nurse effect in seedling establishment: facilitation and tolerance to damage in the Andes of central Chile. Rev. Chil. Hist. Nat. 79, 329-336. doi: 10.4067/S0716-078X2006000300005

Amghar, F., Forey, E., Richard, B., Touzard, B., Laddada, S., Brouri, L., et al. (2016). Old nurses always die: impacts of nurse age on local plant richness. Plant Ecol. 217:407-419. doi: 10.1007/s11258-016-0582-0

Atala, C., Pereira, G., Romero, C., Muñoz-Tapia, L., Vargas, R., and Suz, L. M. (2015). Orchidioid fungi of the form-genus Rhizoctonia associated with the roots of Chloraea cuneata Lindl. from Araucanía, Chile. Gayana. Bot. 72, 145-148. doi: 10.4067/S0717-66432015000100017

Badano, E. I., Cavieres, L. A., Molina-Montenegro, M. A., and Quiroz, C. L. (2005). Slope aspect influences plant association patterns in the Mediterranean matorral of central Chile. J. Arid. Environ. 62, 93-108. doi: 10.1016/j.jaridenv.2004.10.012

Bertness, M. D., and Callaway, R. (1994). Positive interactions in communities. Trends. Ecol. Evol. 9, 191-193. doi: 10.1016/0169-5347(94) 90088-4

Bichsel, R. G., Starman, T. W., and Wang, Y. T. (2008). Nitrogen, phosphorus, and potassium requirements for optimizing growth and flowering of the nobile Dendrobium as a potted orchid. Hort. Sci. 43, 328-332. doi: 10.21273/HORTSCI.43.2.328

Bohman, B., Flematti, G. R., Barrow, R. A., Pichersky, E., and Peakall, R. (2016). Pollination by sexual deception - it takes chemistry to work. Curr. Opin. Plant Biol. 32, 37-46. doi: 10.1016/j.pbi.2016.06.004

Bronstein, J. L. (2009). The evolution of facilitation and mutualism. J. Ecol. 97, 1160-1170. doi: 10.1111/j.1365-2745.2009.01566.x

Brooker, R. W., Maestre, F. T., Callaway, R. M., Lortie, C. J., Cavieres, L. A., Kunstler, G., et al. (2008). Facilitation in plant communities: the past, the present, and the future. J. Ecol. 96, 18-34. doi: $10.1111 /$ j.1365-2745.2007.01295.x

\section{DATA AVAILABILITY STATEMENT}

The datasets analyzed in this manuscript are not publicly available. Requests to access the datasets should be directed to marco.molina@utalca.cl.

\section{AUTHOR CONTRIBUTIONS}

$\mathrm{MB}$ and MM-M conceived and designed the idea. CA and $\mathrm{MB}$ performed and collected data of the experiment in the field. $\mathrm{MB}$ and $\mathrm{MM}-\mathrm{M}$ performed the experiment in the greenhouse. All authors had participation in the data analyses and manuscript writing.

\section{FUNDING}

This work was supported by the project PII20150126 to MM-M.

\section{ACKNOWLEDGMENTS}

The authors thank Victoria Leiva Peña for her technical assistance in the field and Daniel Zunino and María José Romero for their assistance in the greenhouse. MB also thank Dr. Blas Lavandero Icaza from the programm Magister en Ecología Aplicada of Talca University for the guidance in the planning of the experiments.

Bruno, J. F., Stachowicz, J. J., and Bertness, M. D. (2003). Inclusion of facilitation into ecological theory. Trends. Ecol. Evol. 18, 119-125. doi: 10.1016/S0169-5347(02)00045-9

Callaway, R. M. (1995). Positive interactions among plants. Bot. Rev. 61, 306-349. doi: 10.1007/BF02912621

Callaway, R. M. (2007). Positive Interactions and Interdependence in Plant Communities. Dordrecht: Springer.

Cameron, D. D., Leake, J. R., and Read, D. J. (2008). Mutualistic mycorrhiza in orchids: evidence from plant-fungus carbon and nitrogen transfers in the green-leaved terrestrial orchid Goodyera repens. New. Phytol. 171, 405-416. doi: 10.1111/j.1469-8137.2006.01767.x

Cavieres, L. A., Quiroz, C. L., and Molina-Montenegro, M. A. (2008). Facilitation of the non-native Taraxacum officinale by native nurse cushion species in the high Andes of central Chile: are there differences between nurses? Funct. Ecol. 22, 148-156. doi: 10.1111/j.1365-2435.2007.01338.x

Ciotek, L., Giorgis, P., Benitez-Vieyra, S., and Cocucci, A. A. (2006). First confirmed case of pseudocopulation in terrestrial orchids of South America: pollination of Geoblasta pennicillata (Orchidaceae) by Campsomeris bistrimacula (Hymenoptera, Scoliidae). Flora 201, 365-369. doi: 10.1016/j.flora.2005.07.012

Cuevas, J. G., Silva, S. I., León-Lobos, P., and Ginocchio, R. (2013). Nurse effect and herbivory exclusion facilitate plant colonization in abandoned mine tailings storage facilities in north-central Chile. Rev. Chil. Hist. Nat. 86, 63-74. doi: 10.4067/S0716-078X2013000100006

Dallman, P. R. (1998). Plant Life in the World's Mediterranean Climates: The Mediterranean Basin, South Africa, Australia, Chile, and California. Oxford: Oxford University Press.

Flores, J., and Jurado, E. (2003). Are nurse-protégé interactions more common among plants from arid environments? J. Veg. Sci. 14, 911-916. doi: 10.1111/j.1654-1103.2003.tb02225.x

Fox, G. A. (1993). "Failure-time analysis: emergence, flowering, survivorship, and other waiting times," in Design and Analysis of Ecological Experiments, eds S. M. Scheiner and J. Gurevitch (New York,NY: Oxford University Press), 235-266. 
García-Cervigón, A. I., Linares, J. C., Aibar, P., and Olano, J. M. (2015). Facilitation promotes changes in leaf economics traits of a perennial forb. Oecologia 179, 103-116 doi: 10.1007/s00442-015-3312-8

Gómez-Aparicio, L., Gómez, J. M., Regino, Z., and Boettinger, J. L. (2005). Canopy vs. soil effects of shrubs facilitating tree seedlings in Mediterranean montane ecosystems. J. Veg. Sci. 16, 191-198. doi: 10.1111/j.1654-1103.2005.tb02355.x

Gómez-Aparicio, L., Regino, Z., Castro, J., and Hódar, J. A. (2008). Facilitation of tree saplings by nurse plants: microhabitat amelioration or protection against herbivores? J. Veg. Sci. 19, 161-172. doi: 10.3170/2008-8-18347

Gutiérrez, J. R., Meserve, P. L., Kelt, D. A., Engilis, A. Jr., Previtali, M. A., Milstead, W. B., et al. (2010). Investigación de largo plazo en el Parque Nacional Bosque Fray Jorge: veinte años estudiando el rol de los factores bióticos y abióticos en un matorral chileno semiárido. Rev. Chil. Hist. Nat. 83, 69-98. doi: 10.4067/S0716-078X2010000100005

Hágsater, E., and Dumont, V. (1996). Orchids. Status Survey and Conservation Action Plan. Cambridge, UK: IUCN.

Howe, G. A., and Schaller, A. (2008). "Direct defenses in plants and their induction by wounding and insect herbivores," in Induced Plant Resistance to Herbivory, ed A Schaller (Stuttgart: Springer), 7-29. doi: 10.1007/978-1-4020-8182-8_1

Hunter, M. D., and Price, P. W. (1992). Playing chutes and ladders: heterogeneity and the relative roles of bottom-up and top-down forces in natural communities. Ecology 73, 724-732.

Kartzinel, T. R., Trapnell, D. W., and Shefferson, R. P. (2013). Critical importance of large native trees for conservation of a rare neotropical epiphyte. J. Ecol. 101, 1429-1438. doi: 10.1111/1365-2745.12145

Loba, V. C., and Pollmann, S. (2017). "Highly sensitive salicylic acid quantification in milligram amounts of plant tissue," in Plant Hormones, eds J. Kleine-Vehn and M. Sauer (New York, NY:Humana Press), 221-229. doi: 10.1007/978-1-4939-6469-7_18

Louthan, A. M., Doak, D. F., Goheen, J. R., Palmer, T. M., and Pringle, R. M. (2014). Mechanisms of plant-plant interactions: concealment from herbivores is more important than abiotic-stress mediation in an African savannah. Proc. R. Soc. B. Biol. Sci. 281:20132647. doi: 10.1098/rspb.2013.2647

Luebert, F., and Pliscoff, P. (2006). Sinopsis bioclimática y Vegetacional de Chile, 1st $E d n$. Santiago: Editorial Universitaria.

Maestre, F. T., Callaway, R. M., Valladares, F., and Lortie, C. J. (2009). Refining the stress-gradient hypothesis for competition and facilitation in plant communities. J. Ecol. 97, 199-205. doi: 10.1111/j.1365-2745.2008.01476.x

Maxwell, K., and Johnson, G. N. (2000). Chlorophyll fluorescence-a practical guide. J. Exp. Bot. 51, 659-668. doi: 10.1093/jexbot/51.345.659

McCloud, E. S., and Baldwin, I. T. (1997). Herbivory and caterpillar regurgitants amplify the wound-induced increases in jasmonic acid but not nicotine in Nicotiana sylvestris. Planta 203, 430-435. doi: 10.1007/s0042500 50210

Michalet, R., Brooker, R. W., Cavieres, L. A., Kikvidze, Z., Lortie, C. J., Pugnaire, F. I., et al. (2006). Do biotic interactions shape both sides of the humpedback model of species richness in plant communities? Ecol. Lett. 9, 767-773. doi: 10.1111/j.1461-0248.2006.00935.x

Mihoč, M. A. K., Giménez-Benavides, L., Pescador, D. S., Sánchez, A. M., Cavieres, L. A., and Escudero, A. (2016). Soil under nurse plants is always better than outside: a survey on soil amelioration by a complete guild of nurse plants across a long environmental gradient. Plant Soil 408, 31-41. doi: 10.1007/s11104-016-2908-z

Milchunas, D. G., and Noy-Meir, I. (2002). Grazing refuges, external avoidance of herbivory and plant diversity. Oikos 99, 113-130. doi: $10.1034 /$ j.1600-0706.2002.990112.x

Molina-Montenegro, M. A., Muñoz, A. A., Badano, E. I., Morales, B. W., Fuentes, K. M., and Cavieres, L. A. (2005). Positive associations between macroalgal species in a rocky intertidal zone and their effects on the physiological performance of Ulva lactuca. Mar. Ecol. Prog. Ser. 292, 173-180. doi: 10.3354/meps 292173

Molina-Montenegro, M. A., Oses, R., Acuña-Rodríguez, I. S., Fardella, C., Badano, E. I., Torres-Morales, P., et al. (2016a). Positive interactions by cushion plants in high mountains: fact or artifact? J. Plant. Ecol. 9, 117-123. doi: $10.1093 /$ jpe/rtv044
Molina-Montenegro, M. A., Oses, R., Atala, C., Torres-Díaz, C., Bolados, G., and León-Lobos, P. (2016b). Nurse effect and soil microorganisms are key to improve the establishment of native plants in a semiarid community. J. Arid. Environ. 126, 54-61. doi: 10.1016/j.jaridenv.2015.10.016

Myers, N., Mittermeier, R. A., Mittermeier, C. G., Fonseca, G. A., and da, Kent, J. (2000). Biodiversity hotspots for conservation priorities. Nature 403, 853-858. doi: 10.1038/35002501

Novoa, P., Espejo, J., Alarcon, D., Cisternas, M., and Domínguez, E. (2015). Guía de campo de las orquideas chilenas, $2 n d E d n$. Concepción: Corporación Chilena de la Madera (CORMA).

Pliscoff, P., and Fuentes, T. (2008). Análisis de Representatividad Ecosistémica de las áreas Protegidas Públicas y Privadas en Chile. Santiago: GEF, CONAMA y PNUD.

Quintana, J. M., and Aceituno, P. (2012). Changes in the rainfall regime along the extratropical west coast of south America (Chile): 30-43 S. Atmosfera 25, 1-22.

Ramegowda, V., and Senthil-Kumar, M. (2015). The interactive effects of simultaneous biotic and abiotic stresses on plants: mechanistic understanding from drought and pathogen combination. J. Plant. Physiol. 176, 47-54. doi: 10.1016/j.jplph.2014.11.008

Rasmussen, H. N., Dixon, K. W., Jersáková J., and Těšitelová T. (2015). Germination and seedling establishment in orchids: a complex of requirements. Ann. Bot. 116, 391-402. doi: 10.1093/aob/mcv087

Riedemann, M., Teillier, S., and Aldunate, G. (2014). Guía de Campo: Arbustos Nativos Ornamentales del Centro sur de Chile, 1st Edn. Concepción: Corporación Chilena de la Madera (CORMA).

Rundel, P. W., Arroyo, M. T. K., Cowling, R. M., Keeley, J. E., Lamont, B. B., and Vargas, P. (2016). Mediterranean biomes: evolution of their vegetation, floras, and climate. Annu. Rev. Ecol. Evol. Syst. 47, 383-407. doi: 10.1146/annurev-ecolsys-121415-032330

Smith, S. E., and Read, D. J. (2008). Mycorrhizal Symbiosis, 3rd Edn. Great Britain: Academic Press.

Sokal, R., and Rohlf, F. J. (1995). Biometry: the Principies and Practice of Statistics in Biological Research. New York, NY: Freeman Company.

Stancato, G. G. C., Mazzafera, P., and Buckeridge, M. S. (2002). Effects of light stress on the growth of the epiphytic orchid Cattleya forbesii Lindl. X Laelia tenebrosa Rolfe. Rev. Bras. Bot. 3, 229-235. doi: 10.1590/S0100-84042002000200011

Steinfort, U., Verdugo, G., Besoain, X., and Cisternas, M. A. (2010). Mycorrhizal association and symbiotic germination of the terrestrial orchid Bipinnula fimbriata (Poepp.) Johnst (Orchidaceae). Flora - Morphol. Distrib. Funct. Ecol. Plants 205, 811-817. doi: 10.1016/j.flora.2010.01.005

Strauss, S. Y., and Agrawal, A. A. (1999). The ecology and evolution of plant tolerance to herbivory. Trends Ecol. Evol. 14, 179-185. doi: 10.1016/S0169-5347(98)01576-6

Tiffin, P., and Inouye, B. D. (2000). Measuring tolerance to herbivory: accuracy and precision of estimates made using natural versus imoised damage. Evolution 54 , 1024-1029. doi: 10.1554/0014-3820(2000)054[1024:MTTHAA]2.3.CO;2

Wise, M. J., and Abrahamson, W. G. (2005). Beyond the compensatory continuum: environmental resource levels and plant tolerance of herbivory. Oikos 109, 417-428. doi: 10.1111/j.0030-1299.2005.13878.x

Wright, A. J., Wardle, D. A., Callaway, R., and Gaxiola, A. (2017). The overlooked role of facilitation in biodiversity experiments. Trends Ecol. Evol. 32, 383-390. doi: 10.1016/j.tree.2017.02.011

Conflict of Interest: The authors declare that the research was conducted in the absence of any commercial or financial relationships that could be construed as a potential conflict of interest.

Copyright (C) 2019 Baldelomar, Atala and Molina-Montenegro. This is an open-access article distributed under the terms of the Creative Commons Attribution License (CC $B Y)$. The use, distribution or reproduction in other forums is permitted, provided the original author(s) and the copyright owner(s) are credited and that the original publication in this journal is cited, in accordance with accepted academic practice. No use, distribution or reproduction is permitted which does not comply with these terms. 